\title{
Account
}

\section{Significant Improvement of Catalytic Efficiencies in Ionic Liquids}

\author{
Choong Eui Song," Mi Young Yoon, and Doo Seong Choi \\ Institute of Basic Science, Department of Chemistry, Sungkyunkwan University, Suwon, Gyeonggi 440-746, Korea \\ *E-mail: s1673@skku.edu \\ Received June 15, 2005
}

\begin{abstract}
The use of ionic liquids as reaction media can confer many advantages upon catalytic reactions over reactions in organic solvents. In ionic liquids, catalysts having polar or ionic character can easily be immobilized without additional structural modification and thus the ionic solutions containing the catalyst can easily be separated from the reagents and reaction products, and then, be reused. More interestingly, switching from an organic solvent to an ionic liquid often results in a significant improvement in catalytic performance (e.g., rate acceleration, (enantio)selectivity improvement and an increase in catalyst stability). In this review, some recent interesting results which can nicely demonstrate these positive "ionic liquid effect" on catalysis are discussed.
\end{abstract}

Key Words : Ionic liquid, Recycling of catalysts, Rate acceleration, Selectivity enhancement, Catalyst stabilization

\section{Introduction}

Although a number of homogeneous catalysts have gained wide acceptance in terms of their high efficiencies, the cost, toxicity as well as potential for contamination of metal catalysts into the product restrict their use in industry. In order to overcome these drawbacks, a great deal of effort has been devoted into developing effective immobilized catalyst systems. Two main strategies have been employed for the immobilization of homogeneous catalysts. First, the homogeneous catalyst is heterogenized by anchoring it onto a solid support ${ }^{1-3}$ (e.g., an inorganic material or polymer) via (i) a covalent bonding, (ii) adsorption or ion-pair formation, (iii) encapsulation, or (iv) entrapment. Second, liquid-liquid two phase systems can be employed. In the biphasic systems, the catalyst is retained in one phase (e.g., aqueous phase, ${ }^{4}$ fluorous phase, ${ }^{5-7}$ or supercritical carbon dioxide $\left.\left(\mathrm{ScCO}_{2}\right)^{8}\right)$ and the other phase is used for delivery and/or removal of reactant. Quite recently, so-called a "selfsupported strategy" "14 has also been employed for immobilization of homogeneous catalyst. However, immobilization usually affects the catalytic performance of the catalyst. Unfortunately, most examples of immobilized catalysts tend to have inferior catalytic properties to their homogeneous counterparts. Furthermore, most immobilization methodologies need to modify the catalyst structure that raises catalyst costs.

A new approach has recently been developed for catalyst separation and recycling, which involves the use of ionic liquids, i.e., a salt mixture with a melting point below ambient temperature. Ionic liquids are regarded as ecofriendly alternatives to volatile organic solvents in chemical processes, due to their negligible vapor pressure and high thermal stability and non-flammability. Moreover, their hydrophobicities/hydrophilicities and solvent miscibility can be tuned by selecting the appropriate cation and anion. Thus, depending on their structures, they can be designed to be immiscible with water or some organic solvent (e.g., alkanes, ether, $i$ - $\mathrm{PrOH}$, etc.), which renders them more useful for facilitating catalyst recovery from the reaction mixture. More interestingly, switching from an organic solvent to an ionic liquid often results in marked improvements in catalytic performance. ${ }^{15-23}$

A broad range of chemo- and biocatalytic reactions in ionic liquids have already been investigated, and most examples studied to date show that the use of ionic liquids can confer many advantages upon catalytic reactions over reactions in organic solvents in terms of activity, enantioselectivity, stability and the reusability of the solventcatalyst systems. In this review, these recent interesting results on the use of ionic liquids for the catalysis are discussed.
Choong Eui Song has been a Professor at Sungkyunkwan University since 2004. He received a B.S. in 1980 from Chungang University and obtained a Diploma (1985) and a Ph.D. (1988) at RWTH Aachen in Germany. After Ph.D. he worked as a Principal Research Scientist at Korea Institute of Science and Technology (KIST). In 2001 he was appointed as a head of national research laboratory for Green Chirotech- nology in Korea. In 2004 he moved to his current position. His research interests focus on the immobilization of chiral catalysts, ionic liquid chemistry and the development of new pharmaceutically active compounds. He received the academic award from the KIST (2000) and the Scientist of the Month Award from the Ministry of Science and Technology in Korea. 
Most studies in this area have involved the use of 1,3dialkylimidazolium-type ionic liquids $\mathbf{1}$.

$$
\left[\mathrm{R}-\mathrm{N}{ }^{\mathrm{N}-\mathrm{R}^{\prime}}\right]\left[\mathrm{X}^{-}\right] 1
$$

1-Alkyl-3-alkylimidazolium salt $\left(\mathrm{X}=\mathrm{PF}_{6}, \mathrm{SbF}_{6}, \mathrm{NTf}_{2}, \mathrm{BF}_{4}\right.$, OTf, etc. In this article, we have adopted the abbreviations used by many authors for dialkylimidazolium cations, viz., [emim] for 1-ethyl-3methylimidazolium, [bmim] for 1-butyl-3-methylimidazolium, etc.).

\section{Achiral Catalysis in Achiral Ionic Liquids}

Selected Examples for Rate Acceleration, Increased Selectivity and Enhanced Catalyst Stability

1. Metal Triflate-Catalyzed C-C Bond Forming Reactions. Rare earth metal triflate catalyzed C-C bond formation reactions, pioneered by $\mathrm{S}$. Kobayashi, have recently been received considerable attention due to their broad synthetic utility. ${ }^{24}$ However, there are limitations to performing these catalytic reactions on a large scale due to their low turnover numbers (TONs are usually $<10-20$ ). To explore the possibility of repetitive use of catalyst, several polymer- or dendrimer-bound scandium catalysts have very recently been employed. ${ }^{25}$ However, most of the supported scandium catalysts require complicated synthetic manipulations and, moreover, their catalytic activity remains still far from satisfactory.

Recently, several metal triflate-catalyzed C-C bond forming reactions have been conducted in ionic liquids with great success. In most examples studied, a significant rate acceleration and selectivity improvement as well as easy catalyst recycling were observed simply by switching from conventional solvents to ionic liquids.

The following selected examples nicely demonstrate the considerable potential of ionic liquids for metal triflatecatalyzed reactions.

Scandium triflate catalyzed Friedel-Crafts alkylation of aromatic compounds with alkenes: A spectacular effect of ionic liquids influencing positively the catalytic efficiencies has recently been observed by us. The Sc(III) triflate catalyzed Friedel-Crafts alkylation of aromatic compounds with alkenes proceeded readily in the hydrophobic ionic liquid solvents based on 1,3-dialkylimidazolium salts with easy catalyst/solvent recycling, whereas these reactions did not occur in common organic solvents or $\mathrm{H}_{2} \mathrm{O}$ at all. ${ }^{26}$ For example, a 92\% yield of cyclohexylbenzene was obtained from benzene and cyclohexene using $\mathrm{Sc}(\mathrm{OTf})_{3}$ and [bmim] $\left[\mathrm{SbF}_{6}\right]$ (Scheme 1). It is noteworthy here that the rearrangement of alkenes takes place prior to the ring substitution, which indicates that the carbenium ion is formed first. Polarity of these ionic solvents may lead to the stabilization of the polar cationic intermediate.

Metal triflate catalyzed Friedel-Crafts alkenylation of arenes with alkynes: Quite recently, we also observed a dramatic effect of ionic liquids in the metal triflate- catalyzed Friedel-Crafts alkenylation of aromatic compounds with

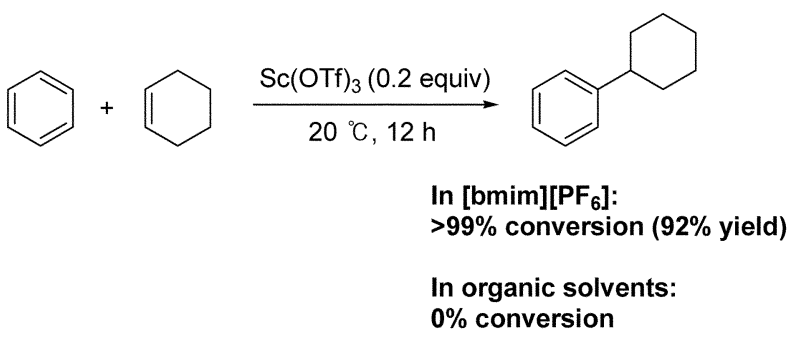

Scheme 1

alkynes. ${ }^{27}$ For example, the alkenylation of benzene with 1phenyl-1-propyne in the presence of $10 \mathrm{~mol} \%$ of $\mathrm{Sc}(\mathrm{OTf})_{3}$ without an ionic liquid proceeded very slowly with a yield of only $27 \%$ after 96 hours. On the other hand, when the reaction was carried out in hydrophobic ionic liquids, such as $[\mathrm{bmim}]\left[\mathrm{PF}_{6}\right]$ or $[\mathrm{bmim}]\left[\mathrm{SbF}_{6}\right]$, the catalytic activity of $\mathrm{Sc}(\mathrm{OTf})_{3}$ was dramatically enhanced: the reaction was completed within 4 hours to afford the desired product $(1,1-$ diphenyl-1-propene) in excellent yields (91 or $90 \%$, respectively). Not only is the catalytic activity significantly enhanced in the ionic liquid, but some reactions that were not possible in conventional organic solvents were shown to proceed smoothly. For examples, the metal-triflate catalyzed alkenylation of the electron-deficient alkynes, such as $p$ trifluoromethylphenylacetylene and $p$-chlorophenylacetylene in ionic liquid proceeded smoothly in $\left[\mathrm{bmim}^{-}\left[\mathrm{SbF}_{6}\right]\right.$, whereas without $[\mathrm{bmim}]\left[\mathrm{SbF}_{6}\right]$ no conversion was observed (Scheme 2). ${ }^{28}$ This significant rate acceleration may be ascribed to the stabilization of the unstable vinyl cationic intermediate in a highly polar ionic liquid, in which the polar vinyl cation may gain a longer lifetime. This method was extended to intramolecular Friedel-Crafts alkenylation in order to prepare coumarins and 2(1H)-quinolinones (Scheme 3). ${ }^{27}$

Scandium triflate catalyzed Diels-Alder reactions: Ionic liquids can act as powerful media (or additives) also in scandium triflate catalyzed Diels-Alder reactions. ${ }^{29}$ For example, the Diels-Alder reaction of 1,4-naphthoquinone with 1,3-dimethylbutadiene in the presence of $0.2 \mathrm{~mol} \%$ of

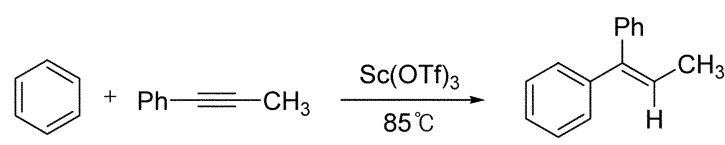

in [bmim] [SbF $698 \%(4 \mathrm{~h})$ without lonic Liquid $27 \%(96 \mathrm{~h})$

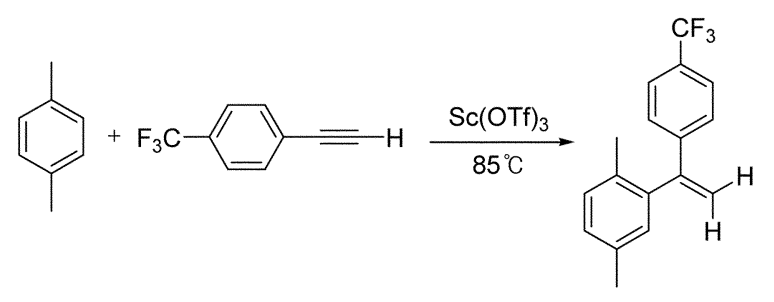

in [bmim] $\left[\mathrm{SbF}_{6}\right] \quad \mathbf{7 3} \%(9 \mathrm{~h})$ without lonic Liquid $0 \%$ 


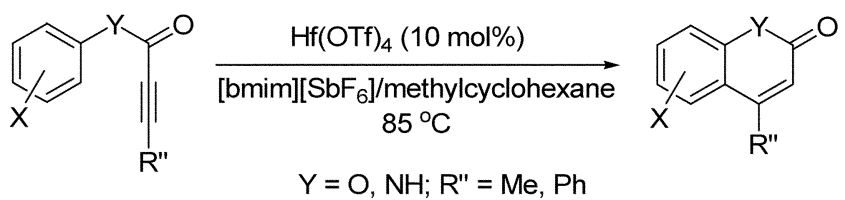

Scheme 3

$\mathrm{Sc}(\mathrm{OTf})_{3}$ in $[\mathrm{bmim}]\left[\mathrm{PF}_{6}\right]$ was completed smoothly within 2 $\mathrm{h}$ at room temperature to give the corresponding Diels-Alder product in $99 \%$ yield whereas the same reaction in $\mathrm{CH}_{2} \mathrm{Cl}_{2}$ is extremely sluggish (Scheme 4). Even use of only $0.1 \mathrm{~mol} \%$ of $\mathrm{Sc}(\mathrm{OTf})_{3}$ catalyst in ionic liquid was sufficient to complete the reaction. This is not only the least recorded amount of catalyst but also the record of extremely rapid reaction in this type of reaction. In common organic solvents such as $\mathrm{CH}_{2} \mathrm{Cl}_{2}, 10-20 \mathrm{~mol} \%$ of $\mathrm{Sc}(\mathrm{OTf})_{3}$ are needed to obtain a similar conversion rate. ${ }^{30}$

Another exciting point of the use of ionic liquids is the significant improvement of the endo/exo selectivity in the studied reactions. For an example, in an ionic liquid, the reaction of 1,4-naphthoquinone with cyclohexadiene proceeded with endo selectively (endo:exo $=>99 / 1$ ). This compares to $94 / 6$ in $\mathrm{CH}_{2} \mathrm{Cl}_{2}$ (Scheme 4). ${ }^{30}$

Baylis-Hillman reaction: Ko et al. studied the BaylisHillman reaction in the presence of 1-butyl-3-methylimidazolium-based ionic liquids. ${ }^{31}$ Most of the ionic liquids studied brought significant rate acceleration. Of various ionic liquids tested, $[\mathrm{bmim}]\left[\mathrm{PF}_{6}\right]$ and $[\mathrm{bmim}][\mathrm{OTf}]$ were found to result in the highest rate increase (ca. 8-10 times rate accelerations) (Scheme 5).

Michael addition of $\beta$-ketoesters to acceptor-activated alkenes: Various 1,3-dicarbonyl compounds undergo smooth conjugate addition to $\alpha, \beta$-unsaturated ketones in the presence of $10 \mathrm{~mol} \%$ copper(II) triflate immobilized in ionic liquid. ${ }^{32}$ Compared to conventional solvents, enhanced reaction rates and improved yields were observed. For example, the reaction of ethyl 2-oxocyclopentane-1-carboxylate with methyl vinyl ketone in the presence of $10 \mathrm{~mol} \%$ copper(II) triflate immobilized in $[\mathrm{bmim}] \mathrm{BF}_{4}$ at room temperature was completed within $4 \mathrm{~h}$ to afford the product in $92 \%$ yield,<smiles>C=C(C)C(=C)C(=O)OC(=O)OC(=O)O</smiles><smiles>CC1=C(C)CC2C(=O)c3ccccc3C(=O)C2C1</smiles>

in [bmim] $\left[\mathrm{PF}_{6}\right]>99 \%(1.5 \mathrm{~h})$ in $\mathrm{CH}_{2} \mathrm{Cl}_{2}<20 \%(1.5 \mathrm{~h})$<smiles>O=C1C=[C+]CC=C1</smiles>

Endo/Exo Ratio: in [bmim] $\left[\mathrm{PF}_{6}\right]>99 / 1$ in $\mathrm{CH}_{2} \mathrm{Cl}_{2}$<smiles>COC(=O)/C=C\C(=O)N1C2CCC1CN(C)C2</smiles><smiles>C=C(C(=O)OC)C(O)c1ccccc1</smiles>

Relative rate

1

8.6

10.1

in $\mathrm{CH}_{3} \mathrm{CN}$ in [bmim $\left[\mathrm{PF}_{6}\right]$ in [bmim][OTf]

Scheme 5<smiles>C=CC(=O)CCC(=O)C1CCCC1(CCC(C)=O)C(=O)OC(C)(Br)Br</smiles>

$92 \%$ yield $(4 \mathrm{~h})$ in [bmim] $\left[\mathrm{BF}_{4}\right]$ $68 \%$ yield $(8 \mathrm{~h})$ in $\mathrm{CH}_{2} \mathrm{Cl}_{2}$

Scheme 6

whereas the same reaction in $\mathrm{CH}_{2} \mathrm{Cl}_{2}$ afforded $68 \%$ yield after $8 \mathrm{~h}$ (Scheme 6).

Reactions of indole with aldehydes/ketones or imines: $\mathrm{Dy}(\mathrm{OTf})_{3}$ immobilized in ionic liquids was found to be an efficient catalytic system for the reactions of indole with a variety of carbonyl compounds and imines. ${ }^{33}$ Significantly enhanced activity was also observed compared to that observed in common solvents. The reaction of indole with heptanal in the ionic liquid, $[\mathrm{bmim}]\left[\mathrm{BF}_{4}\right]$, went to completion within $1 \mathrm{~h}$ at room temperature, affording the product 2 in $95 \%$ of yield, even using $2 \mathrm{~mol} \%$ of Dy(OTf $)_{3}$. However, the same reaction conducted in aqueous ethanol required the increased amount $(10 \mathrm{~mol} \%)$ of catalyst and long reaction time (24 h) (Scheme 7). Furthermore, the use of ionic liquid as solvent permits the product to be easily separated from the catalyst. It has been also reported that $\operatorname{In}(\mathrm{OTf})_{3}$ catalyze same reaction in ionic liquids. ${ }^{34}$

2. Pd-Catalyzed C-C Bond Formation Reactions. In the past few years, several Pd-catalyzed reactions have also been conducted in ionic liquids with great success. In most examples studied, marked improvements in catalytic performance (significant rate acceleration and selectivity improvement as well as easy catalyst recycling) were observed by switching from organic solvents to ionic liquids.

Suzuki cross-coupling reactions: The Suzuki ${ }^{35}$ crosscoupling reaction is an extremely versatile methodology for the generation of new carbon-carbon bonds and is employed most successfully in the synthesis of biaryls. ${ }^{36}$ The reaction, however, suffers from a number of drawbacks such as

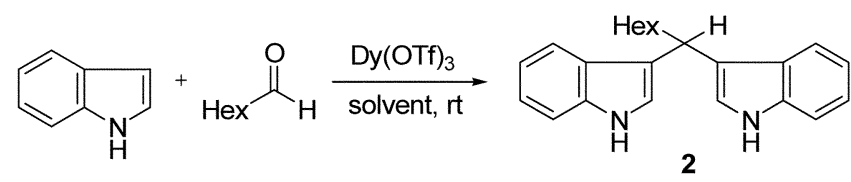

In [bmim] $\left[\mathrm{BF}_{4}\right], 95 \%$ yield $(1 \mathrm{~h})$ using $2 \mathrm{~mol} \%$ of $\mathrm{Dy}(\mathrm{OTf})_{3}$ In EtOH/ $\mathrm{H}_{2} \mathrm{O}, 84 \%$ yield $(24 \mathrm{~h})$ using $10 \mathrm{~mol} \%$ of Dy(OTf $)_{3}$ 
catalyst loss into the product, catalyst decomposition and poor reagent solubilities. These drawbacks have also been solved by the use of ionic liquids.

The reaction of 4-bromobenzene with phenylboronic acid in $[\mathrm{bmim}]\left[\mathrm{BF}_{4}\right]$ with a reduced catalyst concentration, $\mathrm{Pd}\left(\mathrm{PPh}_{3}\right)_{4}(1.2 \mathrm{~mol} \%$, based on arylhalide), afforded biphenyl in a $93 \%$ yield after $10 \mathrm{~min}(\mathrm{TOF} / \mathrm{h}=455)$, without catalyst decomposition (Scheme 8). ${ }^{37}$ This TOF is over 90 times the original activity $(\mathrm{TOF} / \mathrm{h}=5) .{ }^{38}$ In addition, 4methoxybiphenyl is afforded in $40 \%$ in $6 \mathrm{~h}(\mathrm{TOF} / \mathrm{h}=2)$ applying the original conditions. However, in $[\mathrm{bmim}]\left[\mathrm{BF}_{4}\right]$ an $81 \%$ yield is afforded in $10 \mathrm{~min}(\mathrm{TOF} / \mathrm{h}=401)$, which is in the order of 200 times the original activity (Scheme 8). ${ }^{38}$ The reaction can also be achieved with one-tenth the catalyst concentration generally required, $\mathrm{Pd}\left(\mathrm{PPh}_{3}\right)_{4}(0.3 \mathrm{~mol} \%)$. Moreover, homo-coupled products can be eliminated, affording isolated products in high purity avoiding laborious purification procedures. More interestingly, the reactions can also be performed under air without loss of yield or catalyst decomposition.

Palladium-catalyzed carbonylation (alkoxycarbonylation) of aryl halides with alcohols: The palladiumcatalyzed carbonylation reactions of aryl halides with methanol, ethanol or $i-\mathrm{PrOH}$ in the ionic liquid, [bmim]$\left[\mathrm{PF}_{6}\right]$, worked highly efficiently to form the corresponding benzoate in $82 \%$ yield, $91 \%$ and $88 \%$, respectively. ${ }^{39}$ However, the control experiment run in the alcohols resulted in only $30 \%, 32$ and $26 \%$ yield, respectively, suggesting the higher performance of the ionic liquid as reaction medium (Scheme 9). Moreover, as shown in Scheme 10, in ionic liquids, the product selectivity in the carbonylation of aryl halides can be also significantly increased. It has been known that when the carbonylation of aryl halides with isopropanol under higher pressure in a molecular solvents (i.e., isopropanol) forms, in addition to the ester $\mathbf{3}$, the $\alpha$ ketoester 4 via double carbonylation. The increased product selectivity in ionic liquids was explained by more acceleration of single carbonylation forming 3 than the double carbonylation forming the a-ketoester 4 . In addition, the use of ionic liquids also allowed recycling and exhibited catalytic activity even in the seventh run. Thus, total turnover numbers after seventh run reached $c a .1100$.

Dimerization reactions: Also in the Pd-catalyzed dimerization of butadiene a significant rate enhancement was obtained by switching from organic solvents like THF

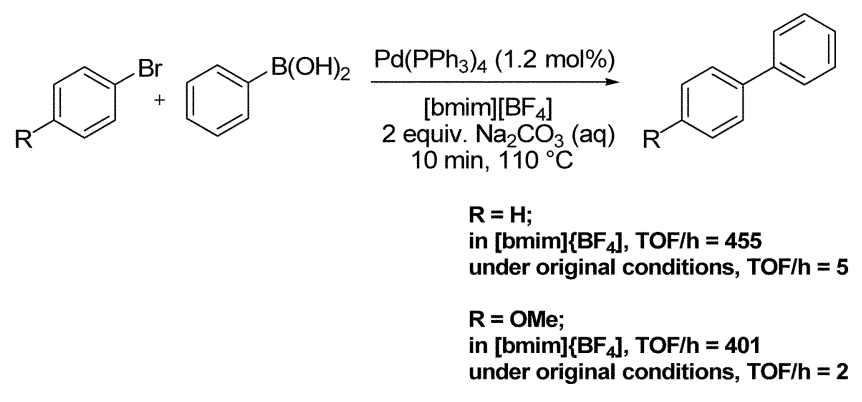

Scheme 8

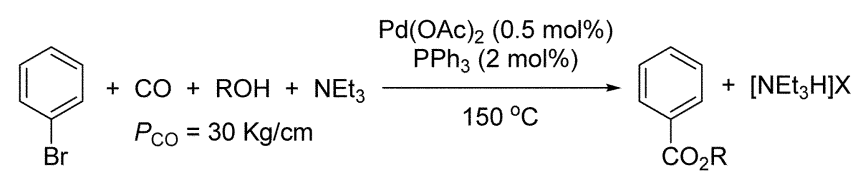

For $\mathrm{ROH}=\mathrm{MeOH}(3 \mathrm{~h})$; $82 \%$ yield in $\left[\mathrm{bmim}^{2}\left[\mathrm{BF}_{4}\right]\right.$ $30 \%$ yield in $\mathrm{MeOH}$ For ROH = EtOH $(6 \mathrm{~h})$; $91 \%$ yield in $\left[b^{b m i m}\right]\left[B_{4}\right]$ $32 \%$ yield in $\mathrm{i}-\mathrm{PrOH}$ For ROH $=\mathrm{i}-\mathrm{PrOH}(6 \mathrm{~h})$ $88 \%$ yield in [bmim] $\left[\mathrm{BF}_{4}\right.$ $26 \%$ yield in $\mathrm{i}-\mathrm{PrOH}$

Scheme 9

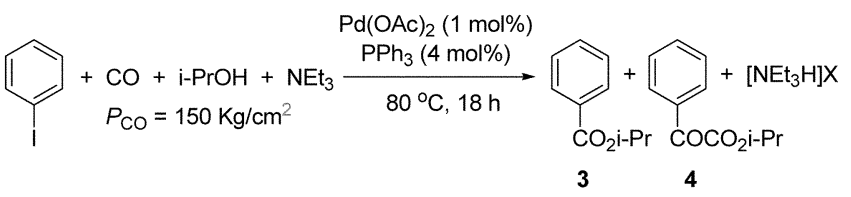

$100 \%(94 \%$ for $3+6 \%$ for 4$)$ yield in [bmim] $\left[\mathrm{PF}_{6}\right]$ $12 \%(5 \%$ for $3+7 \%$ for 4$)$ yield in $\mathrm{MeOH}$

Scheme 10

to imidazolium-based ionic liquids such as $[\mathrm{bmim}]\left[\mathrm{BF}_{4}\right]$. Moreover, the selectivity $(100 \%)$ in $1,3,6$-octatriene is higher than that in homogeneous media (Scheme 11). ${ }^{40}$ For the Pd-catalyzed dimerization of methacrylate, phosphonium-based ionic liquids also show the same rate enhancing effect ( $c a .2$ times rate accelerations) as imidazolium salts. ${ }^{41}$ From all these it was speculated that the ionic medium may lower the activation barrier of the rate determining step by stabilizing the cationic transition state.

Palladium-catalyzed regioselective arylation of an electron-rich olefin by aryl halides: Until now, the Heck arylation of electron-rich olefins by aryl halides has been hampered by very low regioselectivity, unless commercially unavailable and expensive triflates or silver salts are used. However, by employing the ionic liquids such as [bmim]$\left[\mathrm{BF}_{4}\right]$ as the reaction media, highly regioselective arylation was achieved, leading almost exclusively to substitution by various aryl groups at the olefinic carbon $\alpha$ to the heteroatom of butyl vinyl ether (Scheme 12). ${ }^{42,43}$ The key to the success of the chemistry probably lies in the accelerating effect of the ionic liquid on the ionic pathway of the Heck reaction.

Palladium catalyzed Trost-Tsuji $\mathbf{C}-\mathbf{C}$ coupling in ionic liquids: Palladium catalyzed Trost-Tsuji $\mathrm{C}-\mathrm{C}$ coupling of cinnamyl carbonate 7 with ethyl acetoacetate in the ionic liquid, [bmim] $[\mathrm{Cl}]$, brings also several advantages over that in an aqueous catalytic phase: palladium chloride can be

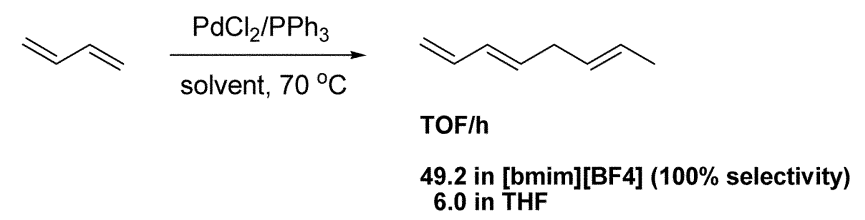

Scheme 11 


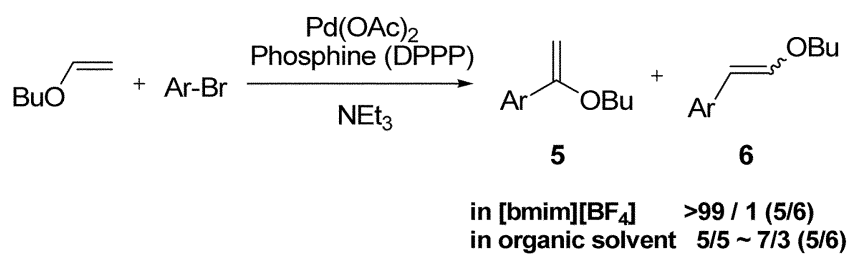

Scheme 12

used as the catalyst precursor instead of the more expensive $\mathrm{Pd}(\mathrm{OAc})_{2}$, the solubility of the organic reagents is much higher which leads to faster reaction rates, and the formation of cinnamyl alcohol 9 coming from the side reaction involving water as a nucleophile is suppressed. Moreover, common organic layers such as simple alkanes instead of nitriles can be used with no noticeable catalyst deactivation. ${ }^{44}$ The yields in the $\mathrm{C}-\mathrm{C}$ product 8 up to $90 \%$ with the TOF number of $23 \mathrm{~h}^{-1}$, thus, was achieved (Scheme 13).

\section{Other Selected Exciting Examples.}

Nucleophilic substitution reactions in ionic liquids: By employing ionic liquids in the nucleophilic substitution reactions such as halogenations, acetoxylation, nitrilation, and alkoxylations, significantly enhanced reactivity and selectivity were observed. ${ }^{45-47}$

For example, the use of the ionic liquid in the nucleophilic fluorination reaction of primary, secondary, and benzylic halides or mesylates with $\mathrm{KF}$ affording the corresponding fluoroalkanes resulted in remarkable rate acceleration and enhanced product selectivity. ${ }^{45}$ For an example, whereas the fluorination of $\mathbf{1 0}$ with $\mathrm{KF}$ in an organic solvent such as $\mathrm{CH}_{3} \mathrm{CN}$ at $100{ }^{\circ} \mathrm{C}$ occurred hardly even after $24 \mathrm{~h}$, the same reaction in ionic liquids, $[\mathrm{bmim}]\left[\mathrm{BF}_{4}\right]$, as a reaction solvent was completed within $1.5 \mathrm{~h}$, affording the wanted product 11 (up to 94\%) (Scheme 14). More interestingly, the use of ionic liquid also suppresses the elimination in the fluorination of haloethyl- or alkanesulfonylethyl aromatic compounds and thus provides a much higher yield of the desired fluoroproduct than in common organic solvents. In common organic solvents, the elimination to styrenes is the dominant reaction. As shown in Scheme 14, the fluorination of 2-(2mesylethyl)naphthalene (12) to 2-(2-fluoroethyl)naphthalene (13) proceeded predominantly and provided the corresponding fluoride in up to $75 \%$ yield, while using the most popular fluorinating reagent, TBAF, only $<10 \%$ of yield could be obtained. ${ }^{48}$ Thus, the use of ionic liquid not only enhanced the nucleophilicity of nucleophile but also

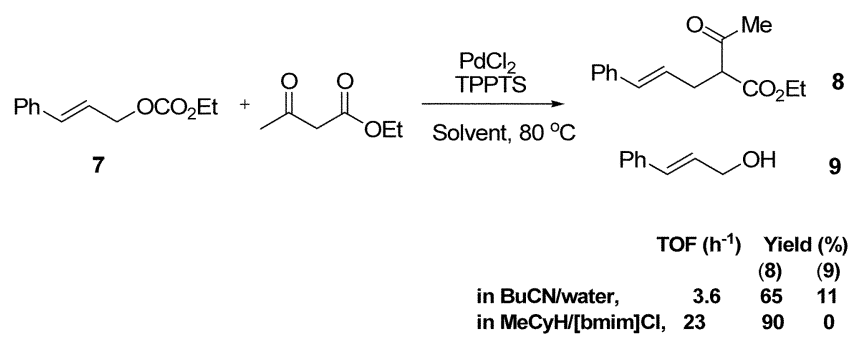

Scheme 13
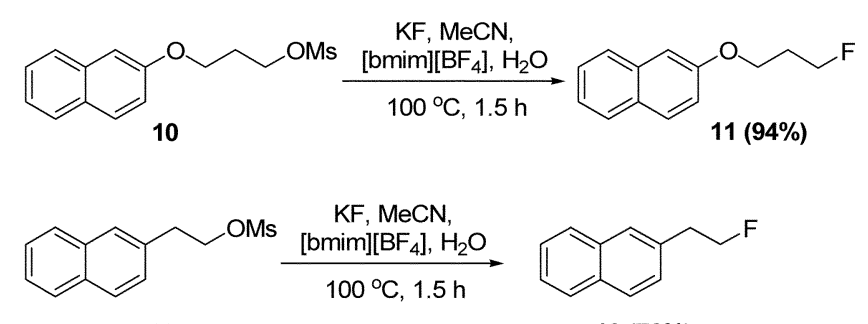

12

$13(76 \%)$

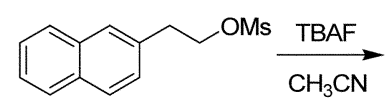

12

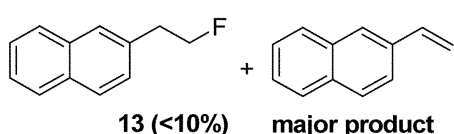

$13(<10 \%)$
Scheme 14

reduced the formation of elimination products which are formed under the conventional basic reaction conditions.

Ionic liquid-catalyzed aziridination of imines with ethyl diazoacetate: Due to their highly regio- and stereoselective ring-opening reactions, aziridines are valued as builing blocks for the synthesis of a wide range of nitrogencontaining compounds. Therefore, a general methodology for one-step formation of aziridines is very useful. However, most methods are based on use of transition metal catalysts or Lewis acid catalysts. Recently, Xia et al. disclosed ${ }^{49}$ an extremely exciting result in which the reaction of imines with ethyl diazoacetate in ionic liquids affords aziridines $\mathbf{1 4}$ in extremlely high yields (93-98\%) without the use of metal catalysts. Moreover, this reaction proceeds with high cis selectivities. When [bmim] $\mathrm{PF}_{6}$ is used, for most of the reactions examined, only the cis aziridines were isolated (Scheme 15). Furthermore, the ionic liquid ([bmim] $\left[\mathrm{PF}_{6}\right]$ ) still retains high conversion and the cis-selectivity during the fifth cycle.

Cycloaddition of styrene derivatives with quinone catalyzed by ferric ion: In the Ferric ion-catalyzed cycloaddition of styrene derivatives with quinone giving 2,3-dihydrobenzofuran derivatives, remarkable acceleration was observed when the reaction was carried out in an ionic liquid. ${ }^{50}$ For example, when the cycloaddition of styrene derivatives 15 with 1,4-benzoquinone was carried out in [bmim $] \mathrm{PF}_{6}$ the desired 2,3-dihydrobenzofuran derivatives 16 with high trans selectivity was obtained by only 3-10 min reaction with excellent yield (up to 98\%), while it took several hours (2-24 h) to complete the same reaction if the reaction was carried out in $\mathrm{CH}_{3} \mathrm{CN}$ solvent (Scheme 16).

\section{Enantioselective Catalysis in Achiral Ionic Liquids}

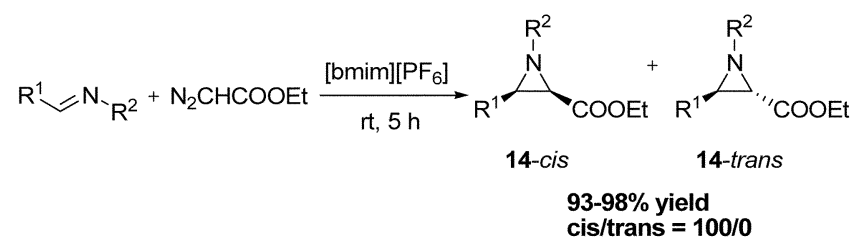

Scheme 15 


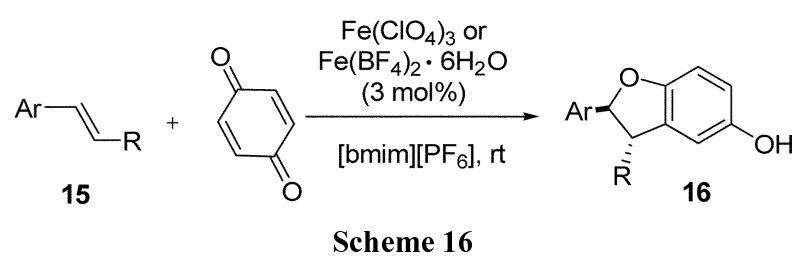

Rate Acceleration in Ionic Liquids. We recently reported for the first time that ionic liquids can accelerate asymmetric epoxidation of olefins catalyzed by the chiral Mn(III)(salen) complex 17. ${ }^{51}$ For example, the epoxidation of 2,2-dimethylchromene using $4 \mathrm{~mol} \%$ of $\mathrm{Mn}(\mathrm{III})($ salen) catalyst in the presence of $\left[\mathrm{bmim}^{\mathrm{b}}\right]\left[\mathrm{PF}_{6}\right]$ was completed in $2 \mathrm{~h}$, whereas the same reaction without the ionic liquid, required $6 \mathrm{~h}$ to achieve complete conversion. This rate acceleration effect induced by the ionic liquid was shown even more dramatically when the amount of the catalyst was reduced to $0.5 \mathrm{~mol} \%$ (Scheme 17). ${ }^{52}$ In a mixture of $\left[\mathrm{bmim}^{2}\right]\left[\mathrm{PF}_{6}\right]$ and $\mathrm{CH}_{2} \mathrm{Cl}_{2}(1: 4 \mathrm{v} / \mathrm{v})$, the above reaction was completed in $6 \mathrm{~h}$, whereas without the ionic liquid only $c a .40 \%$ conversion was observed in the same time. Moreover, the use of an ionic liquid solvent allows for easier catalyst recycling, without the need for catalyst modification. By washing the organic phase with water, concentrating the organic phase, and then extracting the product with hexane, the ionic catalyst solution can be recovered. However, the enantioselectivity and activity of the recovered catalyst decreased upon reuse. After five cycles, the yield and enantioselectivity dropped from $83 \%$ to $53 \%$ and from $96 \%$ ee to $88 \%$ ee, respectively. This deterioration may be due to degradation of the salen catalyst under oxidation conditions. Nevertheless, to the best of our knowledge, Jacobsen's catalyst immobilized in an ionic liquid constitutes one of the most efficient and recyclable catalytic systems available for the asymmetric epoxidation of alkenes.

Selected Examples for Increased Enantioselectivity in Ionic Liquids. Jessop et al. have shown that ionic liquids can enhance the enantioselectivity in the asymmetric reduction of tiglic acid using Ru-tolBINAP catalyst $18 .^{53}$ Using the viscous ionic liquids such as $[\mathrm{bmim}]\left[\mathrm{PF}_{6}\right]$ and [emim] $\left[\mathrm{NTf}_{2}\right]$, the ee's reported were found to increase from

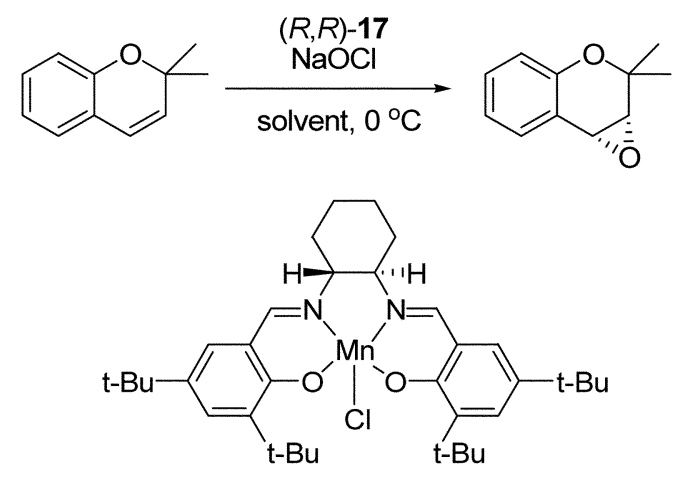

$(R, R)-17$
$88 \%$ in $\mathrm{MeOH}$ to 93 and $95 \%$, respectively (Scheme 18). It has been known that tiglic acid is one of those substrates which requires a low $\mathrm{H}_{2}$ concentration or low $\mathrm{H}_{2}$ pressure for optimum selectivity. ${ }^{54,55}$ Thus, the increased ee's in viscous ionic liquids can be attributed to a lower concentration of $\mathrm{H}_{2}$ in ionic liquid during reaction. $\mathrm{MeOH}$ or a less viscous ionic liquid such as $[\mathrm{bmim}]\left[\mathrm{BF}_{4}\right]$ has lower surface tension, and is better able to dissolve $\mathrm{H}_{2}$ gas which consequently results in a lower enantioselectivity.

Asymmetric Diels-Alder reactions of oxazolidinone 19 and cyclopentadiene using platinum complexes $\mathbf{2 0}$ and $\mathbf{2 1}$ of conformationally flexible NUPHOS-type diphosphines or BINAP have been compared in $\mathrm{CH}_{2} \mathrm{Cl}_{2}$ and selected ionic liquids. ${ }^{56}$ Significant enhancements in the enantioselectivity were achieved in ionic liquids compared with the organic media. For example, reactions in [emim] $\left.\mathrm{NTf}_{2}\right]$ gave ees of 90-92\%, whereas the corresponding reactions in $\mathrm{CH}_{2} \mathrm{Cl}_{2}$ only gave ees of $67-84 \%$. Moreover, all reactions performed in ionic liquids were significantly faster than those performed in $\mathrm{CH}_{2} \mathrm{Cl}_{2}$. In most ionic liquids, nearly quantitative conversions were achieved within only $1 \mathrm{~h}$ at $20^{\circ} \mathrm{C}$. On the other hand, when the reactions were carried out in $\mathrm{CH}_{2} \mathrm{Cl}_{2}$, much lower conversions (22-45\%) were observed even after

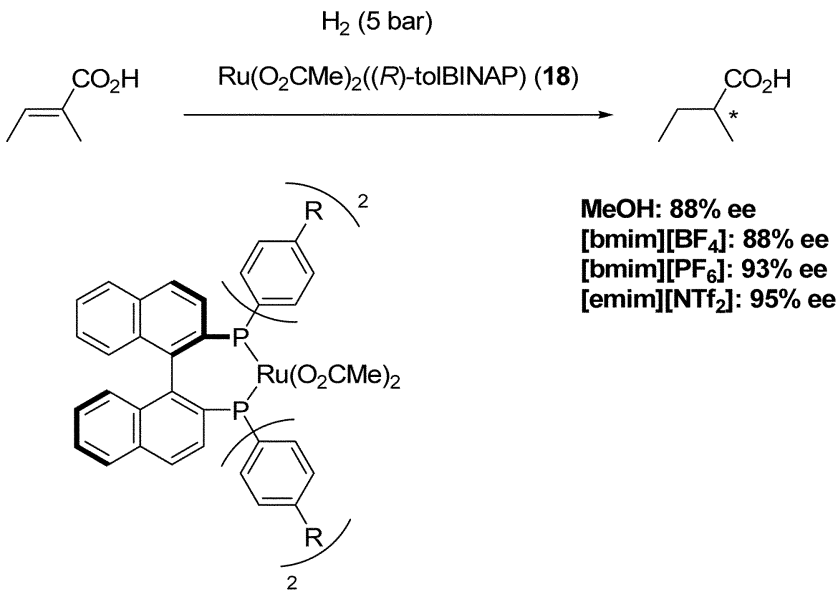

18: $\mathrm{Ru}\left(\mathrm{O}_{2} \mathrm{CMe}\right)_{2}((R)$-tolBINAP)

Scheme 18

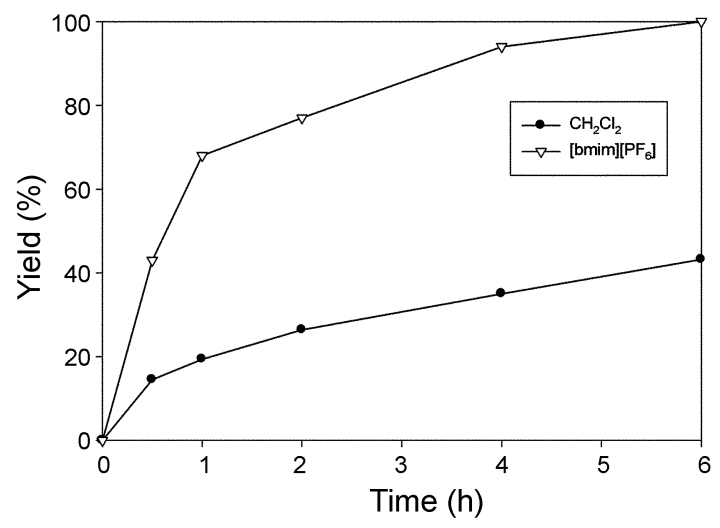

Scheme 17. Kinetic studies in the epoxidation of 2,2'-dimethylchromene in the presence of $0.5 \mathrm{~mol} \%$ of $(R, R)$-17 using NaOCl as cooxidant in $\mathrm{CH}_{2} \mathrm{Cl}_{2}$ or $[\mathrm{bmim}]\left[\mathrm{PF}_{6}\right] / \mathrm{CH}_{2} \mathrm{Cl}_{2}(1: 4 \mathrm{v} / \mathrm{v})$ at $0{ }^{\circ} \mathrm{C}$. 
<smiles>C/C=C/C(=O)N1CCCC1=O</smiles>
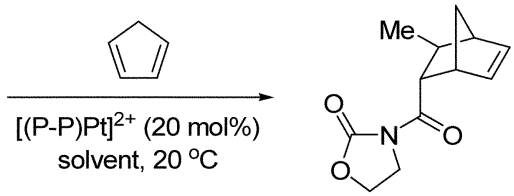

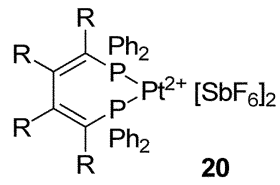

\section{For $\delta-20(\mathrm{R}=\mathrm{Ph})$}

in $\mathrm{CH}_{2} \mathrm{Cl}_{2} ; 45 \%$ yield $(20 \mathrm{~h}), 67 \%$ ee $(2 R)$ in [emim][NTf $]$ ]; $100 \%$ yield $(1 \mathrm{~h}), 90 \%$ ee $(2 R)$

For $\lambda-20(\mathrm{R}=\mathrm{Me})$

in $\mathrm{CH}_{2} \mathrm{Cl}_{2} ; 22 \%$ yield $(20 \mathrm{~h}), 71 \%$ ee $(2 \mathrm{~S})$ in [emim][NTf $]$; $90 \%$ yield $(1 \mathrm{~h}), 91 \%$ ee $(2 R)$<smiles></smiles>

For (S)-21

in $\mathrm{CH}_{2} \mathrm{Cl}_{2} ; 37 \%$ yield $(20 \mathrm{~h}), 84 \%$ ee $(2 R)$ in [emim][ $\left[\mathrm{NTf}_{2}\right.$ ]; $100 \%$ yield $(1 \mathrm{~h}), 92 \%$ ee $(2 R)$

21

\section{Scheme 19}

$20 \mathrm{~h}$ (Scheme 19).

Meracz and Oh also observed an markedly increased ee (92\% ee) for the Diels-Alder reaction of oxazolidinone 19 and cyclopentadiene using a rigid copper bisoxazoline-based chiral Lewis acid 22 with a yield of $65 \%$ in 1,3dibutylimidazolium tetrafluoroborate ([dibuim $]\left[\mathrm{BF}_{4}\right]$ ). ${ }^{57}$ This was compared with the reaction in dichloromethane, which showed only $52 \%$ ee with a yield of only $4 \%$. Moreover, a much higher endo-exo ratio $(93: 7)$ was also observed in the ionic liquid than that $(79: 21)$ obtained in $\mathrm{CH}_{2} \mathrm{Cl}_{2}$ (Scheme 20).

Recently, Toma et al. ${ }^{58,59}$ performed the enantioselective Pd-catalyzed allylic substitution in the presence of ionic liquids and observed an significant increase in enantioselectivity versus that achieved in organic solvent. For example, chiral Pd-ferrocenylphosphine complexes such as the BPPFA (23)-Pd complex catalyzed the allylic substitution of (rac)-(E)-1,3-diphenyl-3-acetoxypro-1-ene in [bmim $]\left[\mathrm{PF}_{6}\right]$ to give the product with $68 \%$ ee, which was higher than that $(40 \%$ ee) observed in THF (Scheme 21$) .{ }^{58}$

Recently it was found that a simple amino acid such as proline catalyzes the direct asymmetric aldol reaction. ${ }^{60,61}$ However, a very low turnover number (ca. 3) and a strong solvent influence on the chemo- and enantioselectivity limits the use of this reaction in large-scale processes. In attempt to

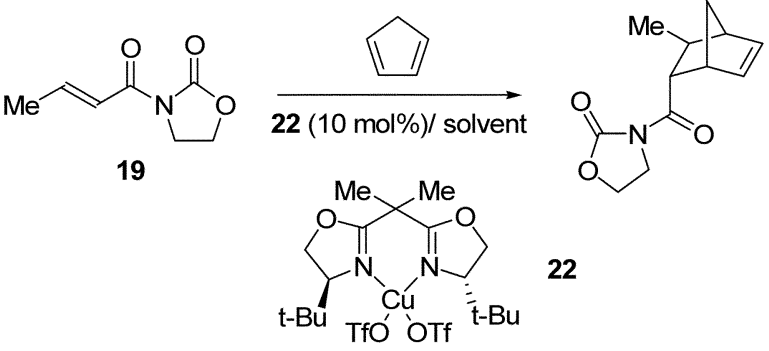

solvent $=\mathrm{CH}_{2} \mathrm{Cl}_{2} ; 4 \%$ yield, endo:exo $=79: 21,52 \%$ ee solvent $=[$ dibuim $]\left[\mathrm{BF}_{4}\right] ; 65 \%$ yield, endo:exo $=96: 4,92 \%$ ee

Scheme 20

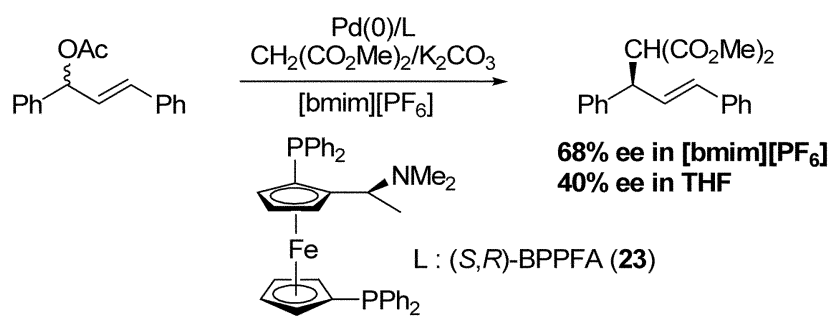

Scheme 21

recover and reuse the proline catalyst, it was immobilized on a silica surface, ${ }^{62}$ however, a significant reduction in enantioselectivity was observed. Recently, two research groups $^{63,64}$ reported independently that this reaction can be carried out successfully in ionic liquids with comparable or better ee's than those obtained in organic solvents. For example, the benzaldehyde aldol product with acetone was obtained with $71 \%$ ee $^{63}(76 \%$ ee in ref. 64$)$ in $\left[\mathrm{bmim}^{6}\left[\mathrm{PF}_{6}\right]\right.$. However, a lower ee $(60 \%)$ was obtained in DMSO. ${ }^{60,61}$ After reaction, the immobilized proline in the ionic liquid phase was simply recovered and reused in subsequent reactions without a significant loss of activity and enantioselectivity (Scheme 22).

Recently, the chiral bis(oxazoline) (24)-Cu-catalyzed enantioselective cyclopropanation of styrene with ethyl diazoacetate was studied in ionic liquids with a view toward catalyst recycling. ${ }^{65}$ The interesting effect of ionic liquids was demonstrated by the result obtained with bis(oxazoline) (24) $-\mathrm{CuCl}_{2}$ complex dissolved in $[\mathrm{emim}]\left[\mathrm{NTf}_{2}\right]$. Both yield and enantioselectivity were much higher than those obtained with $\mathrm{CuCl}_{2}$ in $\mathrm{CH}_{2} \mathrm{Cl}_{2}$, and were similar to those obtained with $\mathrm{Cu}(\mathrm{OTf})_{2}$ complex (Table 1). This result seems to indicate that the active species is the $\mathrm{Cu}\left(\mathrm{NTf}_{2}\right)$ complex of bis(oxazoline) (24). The $\mathrm{NTf}_{2}$ anion seems to behave more like triflate than chloride. Therefore, this method provides a clear advantage in that inexpensive $\mathrm{CuCl}_{2}$ can be used instead of the expensive and moisture-sensitive $\mathrm{Cu}\left(\mathrm{OTf}_{2}\right)$. Moreover, the complex dissolved in $[\mathrm{emim}]\left[\mathrm{NTf}_{2}\right]$ was successfully recycled twice without loss of activity and enantioselectivity.

Selected Examples for Enhanced Catalyst Stability. Recently, we observed that ionic liquids can also stabilize certain catalytic oxidation state. ${ }^{66}$ In the hydrolytic kinetic resolution (HKR) of racemic epoxides using catalytic amounts of $(R, R)-\mathrm{Co}(\mathrm{III})($ salen $) \cdot \mathrm{OAc}((R, R)-25-\mathrm{OAc})$ in a mixture $(4 / 1, \mathrm{v} / \mathrm{v})$ of THF and an ionic liquid, [bmim] $] \mathrm{X}](\mathrm{X}$ $\left.=\mathrm{PF}_{6}, \mathrm{NTf}_{2}\right)$, at $20^{\circ} \mathrm{C}$, the yields and enantiomeric excesses
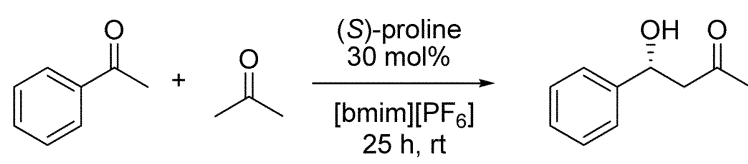

$58 \%, 71 \%$ ee ( 1 st run) $56 \%, 71 \%$ ee (2nd run) $53 \%, 69 \%$ ee (3rd run) $52 \%, 67 \%$ ee (4th run) 
Table 1. The asymmetric cyclopropanation of styrene with ethyl diazoacetate catalyzed by bis(oxazoline) 24-copper complexes

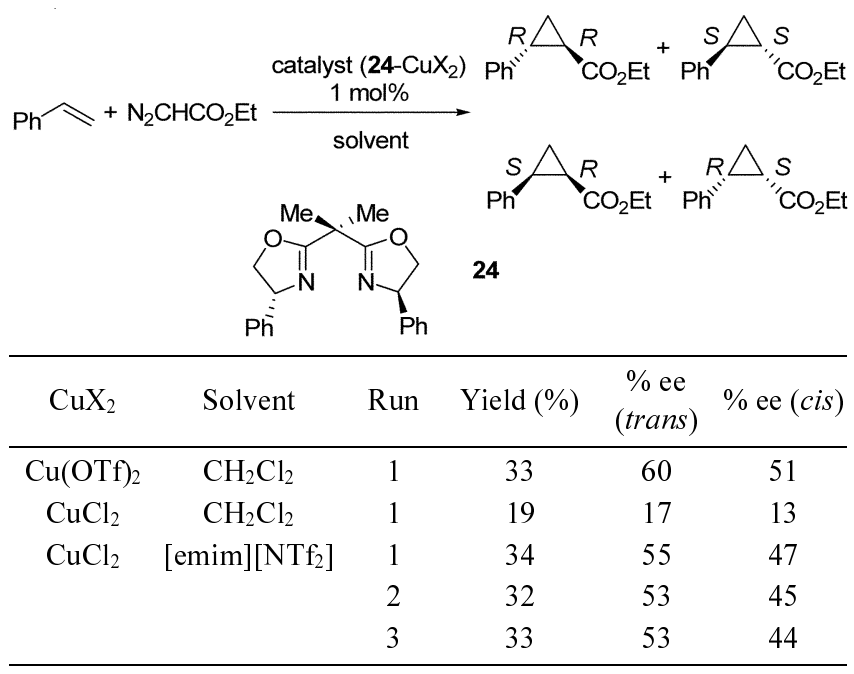

were quite comparable to those obtained without ionic liquids (Scheme 23).

Interestingly, it was found by UV and XPS analysis of the recovered ionic liquid phase that the oxidation state of the $\mathrm{Co}$ (salen) complex dissolved in the recovered ionic liquid phase was not + II, but + III. On the other hand, it has been well known that when organic solvents are used as the reaction media, $(R, R)-\mathbf{2 5}-\mathrm{OAc}$ is reduced to the $\mathrm{Co}(\mathrm{II})$ (salen)complex $(R, R)-\mathbf{2 5}$ during the HKR reactions. More interestingly, it was also found that catalytically inactive $\mathrm{Co}(\mathrm{II})$ (salen) complex $(R, R)-\mathbf{2 5}$ can be directly used as a catalyst precursor instead of $(R, R)$-25-OAc catalyst in the presence of the ionic liquid. The $\mathrm{Co}(\mathrm{II})($ salen) complex is oxidized, in the absence of acetic acid, to the catalytically active $\mathrm{Co}$ (III) complex during the HKR reactions, which may not be possible in conventional organic solvents. Thus, all HKRs of racemic epichlorohydrin using catalytic amounts of $\mathrm{Co}(\mathrm{II})($ salen $)$ complex $((R, R)-25)$ in $\left[\mathrm{bmim}^{2}\left[\mathrm{PF}_{6}\right]\right.$ or
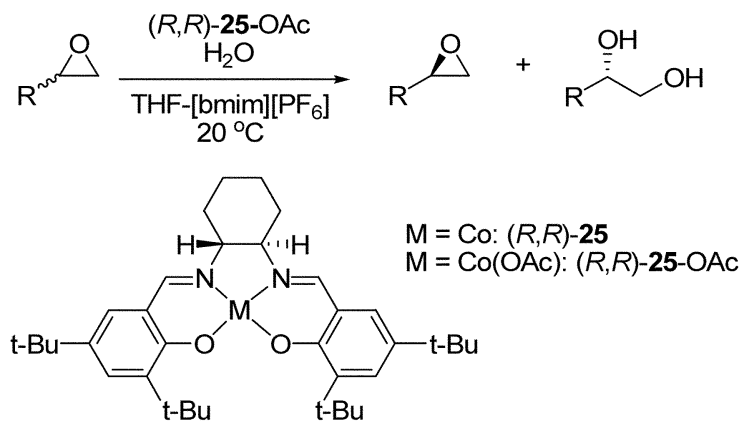

Example:

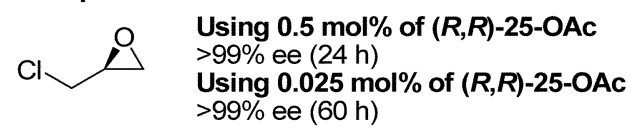

Scheme 23 [bmim $]\left[\mathrm{NTf}_{2}\right]$ proceeded smoothly, even when only 0.025 $\mathrm{mol} \%$ of $(R, R)-\mathrm{Co}(\mathrm{II})$ (salen) was used. For example, enantiomerically pure epichlorohydrin was obtained after 70 $\mathrm{h}$ using $0.025 \mathrm{~mol} \%$ of $\mathrm{Co}(\mathrm{II})$ (salen) complex. Here again, the catalytically active $\mathrm{Co}$ (III) oxidation state is stabilized against reduction to the $\mathrm{Co}$ (II) complex, which enables the reuse of the recovered catalyst for subsequent runs without additional re-oxidation. This catalytic system involving the ionic liquid $[\mathrm{bmim}]\left[\mathrm{NTf}_{2}\right]$ was reusable up to ten times without any loss of activity and enantioselectivity ( $>99 \%$ ee) (Scheme 24). However, it is not clear yet why, in the presence of an ionic liquid, the Co(II) complex is oxidized without the use of acetic acid during the reaction to the catalytically active Co(III) complex and why this oxidation state is maintained.

Recently, Guernik et al. reported upon the catalyst stabilization effect of an ionic liquid in the asymmetric hydrogenation of olefins. ${ }^{67} \mathrm{Rh}-\mathrm{MeDuPHOS}$ (26) complex immobilized in $[\mathrm{bmim}]\left[\mathrm{PF}_{6}\right]$ was found to catalyze the asymmetric hydrogenation of enamides (methyl $\alpha$ acetamidoacrylate and methyl $\alpha$-acetamidocinnamate) with enantioselectivities similar to those obtained using the same catalyst dissolved in organic solvent $(i-\mathrm{PrOH})$. Interestingly, the ionic liquid stabilized this highly air-sensitive catalyst, enabling all experiments including catalyst recycling to be carried out in a normal atmosphere without any significant loss of enantioselectivity (e.g., methyl $\alpha$-acetamidocinnamate as the substrate, $96 \%$ ee for the first run and $94 \%$ ee for the fifth run) (Scheme 25). On the other hand, in the absence of the ionic liquid, when a catalyst prepared in an inert atmosphere was exposed to air for a few minutes it almost totally lost its catalytic activity. This stabilizing effect of the ionic liquid is considered to be due to the entrapment of the air-sensitive complex in the ionic liquid, i.e., ionic liquids can protect the air-sensitive complex from attack by atmospheric oxygen.

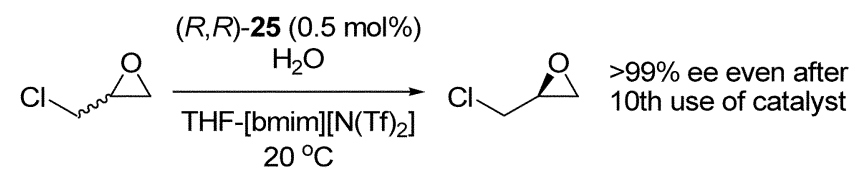

Scheme 24

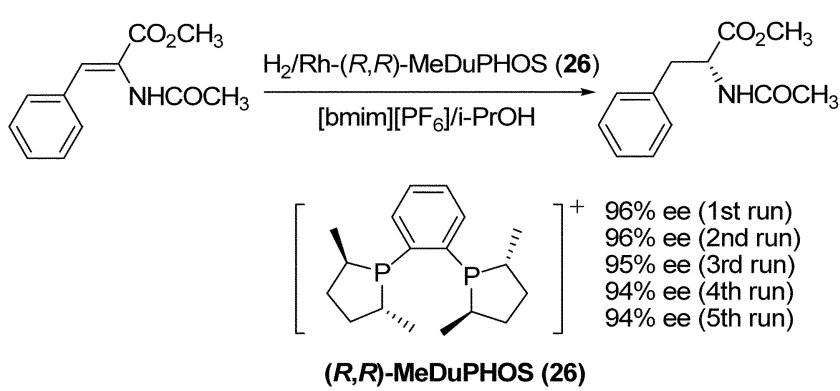

"All manipulations were performed in air."

Scheme 25 


\section{Enantioselective Biocatalysis in Achiral Ionic Liquids}

Another exciting recent development in the use of ionic liquids is the application of enantioselective biocatalysis in these solvents. Although only a small range of enzymes (mainly lipases) have been investigated to date, the results reported so far suggest that the use of ionic liquids as solvents in enzymatic reactions can also provide many advantages. In lipase-catalyzed reactions, in particular, the enantioselectivity and operational stability are often much better than in traditional media. The reason for the improvement of catalytic performances of enzymes in ionic liquids may be related to their ionic nature. Ionic liquids are likely to interact with the enzyme's charged groups, either at the active site or at its periphery (microenvironment), thus inducing changes in enzyme's structure. Recent review articles by us and others are well described on this topic, ${ }^{15,68}$ and thus, enantioselective biocatalysis in ionic liquids will not be discussed in detail here.

\section{Enantioselective Catalysis in Chiral Ionic Liquids}

Recently, some examples of chiral ionic liquids have been prepared with aim of their use as chiral solvents in enantioselective organic chemistry. ${ }^{17}$ Due to their high degree of organization caused by three-dimensional networks of anions and cations linked together by hydrogen bonds, a more efficient chirality transfer in these solvents than in traditional chiral solvents might be expected. Recent examples for strong diastereomeric interactions between chiral ionic liquids and a racemic substrate observed by NMR demonstrate the possibility of chiral recognition ability of the chiral ionic liquids. ${ }^{17}$ However, very few applications of the chiral ionic liquids as solvents or chiral inducers have been described so far and, moreover, most attempts at carrying out enantioselective reactions using chiral ionic liquids failed to produce an significant asymmetric induction.

In 1997, Howarth et al. reported $^{69}$ the first example of a chiral ionic liquid, 3-bis-((S)-2-methyl-butyl)-1H-imidazol1-ium bromide (27), and its evaluation as Lewis acid in asymmetric Diels-Alder reactions between crotonaldehyde or methacrolein and cyclopentadiene. However, attempts at carrying out enantioselective Diels-Alder reactions using this ionic liquid as a chiral Lewis acid ( 0.2 equiv.) failed to produce an enantiomeric excess superior to $5 \%$.

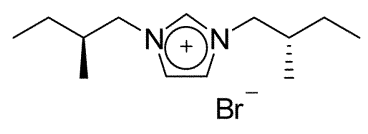

27

The first example of the use of chiral ionic liqsuids as reaction media in the asymmetric Baylis-Hillman reaction was described using $N$-alkyl- $N$-methylephedrinium salts 28 . Good yields, but only moderate enantiomeric excesses were obtained (Scheme 26). ${ }^{70}$

Very recently, Ding et al. ${ }^{71}$ prepared $N, N$-dimethyl-

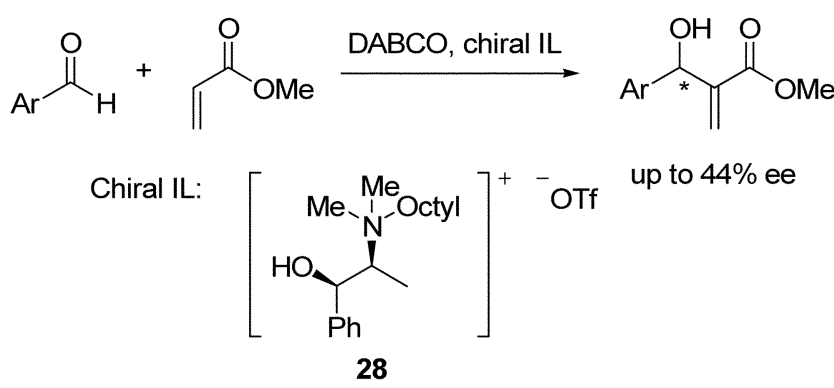

Scheme 26

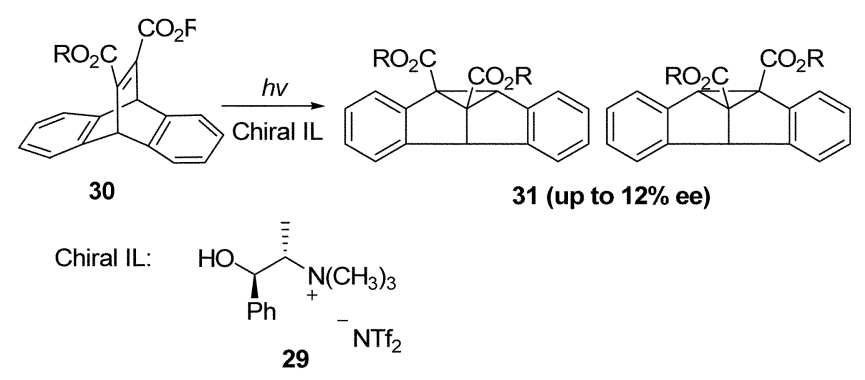

Scheme 27

ephedrinium salts $\mathbf{2 9}$ and used to control the stereoselectivity of the photoisomerization of dibenzobarrelenedicarboxylates (30) $(\mathrm{R}=\mathrm{H}, \mathrm{Me})$ to the dibenzotricyclooctenedicarboxylates (31). Photoisomerization of $\mathbf{3 0}(\mathrm{R}=\mathrm{H})$ in chiral ionic liquids, and often in the presence of additives such as $\mathrm{N}, \mathrm{N}$-dimethylbenzylamine, gives di- $\pi$-methane rearrangement product $31(\mathrm{R}=\mathrm{H})$ in up to $12 \%$ ee (Scheme 27). This chiral induction may be attributed to ion pairing interactions between the deprotonated diacid and the ionic liquid cations.

\section{Conclusion}

The results discussed here demonstrate the considerable potential of ionic liquids as alternative reaction media for catalysis. The use of ionic liquid solvents allows catalysts to be recycled more easily. Moreover, in many cases, ionic liquids exhibited a positive influence on the catalytic properties, as the reactions can be accelerated in suitable ionic solutions with improved (enantio) selectivities. Increased stability of catalyst or of enzyme was also observed in the ionic liquids. Obviously, these positive "ionic liquid effect" on catalysis is due to the unique catalytic environment imposed by an ionic liquid, causing positive changes of the reaction course. However, more detailed studies are necessary to establish the exact reasons behind these observed advantages. In the last part of this review, applications of the chiral ionic liquids as chiral solvents or chiral inducers were described. Although most attempts until now to produce a high enantioselectivity using chiral ionic liquids failed, more studies in this field should be done to find the real potential of chiral ionic liquids in asymmetric synthesis. 
Acknowledgement. This work was supported by Brain Korea 21 project and the SRC program of MOST/KOSEF (R11-2005-008-00000-0).

\section{References}

1. Song, C. E.; Lee, S.-g. Chem. Rev. 2002, 102, 3495-3524.

2. Song, C. E.; Park, I. S. In Advances in Organic Synthesis; Bentham Publishers: 2005; Chap. 8.

3. Song, C. E. In Annual Report C 2005, 1-28.

4. Cornils, B.; Herrmann, W. A. Aqueous-Phase Organometallic Catalysis; VCH: New York, 1998.

5. Horvath, I. T. Acc. Chem. Res. 1998, 31, 641-650.

6. Curran, D. P. Angew. Chem. Int. Ed. Engl. 1998, 37, 1174-1196.

7. Curran, D. P. Synlett 2001, 1488-1496.

8. Jessop, P. G.; Ikariya, T.; Noyori, R. Chem. Rev. 1999, 99, 475494.

9. Wang, X.; Ding, K. J. Am. Chem. Soc. 2004, 126, 10524.

10. Liang, Y.; Jing, Q.; Li, X.; Shi, L.; Ding, K. J. Am. Chem. Soc. 2005, 127, 7694-7695.

11. Dioumaev, V. D.; Bullock, M. Nature 2000, 424, 530 .

12. Yang, J. W.; Han, H.; Roh, E. J.; Lee, S.-g.; Song, C. E. Org. Lett. 2002, 4, 4685-4688.

13. Jo, C. H.; Han, S.-H.; Yang, J. W.; Roh, E. J.; Shin, U.-S.; Song, C. E. Chem. Commun. 2003, 1312-1313.

14. Song, C. E.; Jung, D.; Roh, E. J.; Lee, S.-g.; Chi, D. Y. Chem. Commun. 2002, 3038-3039.

15. Song, C. E. Chem. Commun. 2004, 1033-1043.

16. Song, C. E. In Methodologies in Asymmetric Catalysis; Malhotra, S. V., Ed.; ACS Symposium Series 880, 2004; pp 145-160.

17. Baudequin, C.; Baudoux, J.; Levillain, J.; Cahard, D.; Gaumont, A.-C.; Plaquevent, J.-C. Tetrahedron: Asymmetry 2003, 14, 30813093.

18. Ionic Liquids in Synthesis; Wasserscheid, P.; Welton, T., Eds.; Wiley-VCH: Weinheim, 2003.

19. Ionic Liquids: Industrial Applications for Green Chemistry; Rogers, R. D.; Seddon, K. R., Eds; ACS Symposium Series 818, 2002.

20. Dupont, J.; de Souza, R. F.; Suarez, P. A. Z. Chem. Rev. 2002, 102, 3667-3692.

21. Sheldon, R. Chem. Commun. 2001, 2399-2407.

22. Wasserscheid, P.; Keim, W. Angew. Chem. Int. Ed. 2000, 39, 3772-3789.

23. Welton, T. Chem. Rev. 1999, 99, 2071-2084

24. Kobayashi, S. Chem. Rev. 2002, 102, 2227-2302.

25. Kobayashi, S. Chem. Commun. 2003, 449-460.

26. Song, C. E.; Shim, W. H.; Roh, E. J.; Choi, J. H. Chem. Commun. 2000, 1695-1696.

27. Song, C. E.; Jun, D.; Choung, S.-Y.; Roh, E. J.; Lee, S.-g. Angew. Chem. Int. Ed. 2004, 43, 6183-6185.

28. Tsuchimoto, T.; Maeda, T.; Shirakawa, E.; Kawakami, Y. Chem. Commun. 2000, 1573-1574.

29. Song, C. E.; Shim, W. H.; Roh, E. J.; Lee, S.-g.; Choi, J.-H. Chem. Commun. 2001, 1122-1123.

30. Kobayashi, S.; Hachiya, I.; Araki, M.; Ishitani, H. Tetrahedron Lett. 1993, 34, 3755.

31. Kim, E. J.; Ko, S. Y.; Song, C. E. Helv. Chim. Acta 2003, 86, 894899

32. Yadav, J. S.; Reddy, B. V. S.; Baishya, G.; Narsaiah, A. V. Chem. Lett. 2005, 34, 102-103.

33. Mi, X.; Luo, S.; Hea, J.; Chenga, J.-P. Tetrahedron Lett. 2004, 45, $4567-4570$

34. Ji, S. J.; Zhou, M. F.; Gu, D. G.; Wang, S. Y.; Loh, T. P. Synlett 2003, 13, 2077-2079.

35. Miyaura, N.; Suzuki, A. Chem. Rev. 1995, 95, 2457.
36. Stanforth, S. P. Tetrahedron 1998, 54, 263 and references therein.

37. Mathews, C. J.; Smith, P. J.; Welton, T. Chem. Commun. 2000, 1249-1250.

38. Miyaura, N.; Yanagi, T.; Suzuki, A. Synth. Commun. 1981, 11, 513.

39. Mizushima, E.; Hayashi, T.; Tanaka, M. Green Chem. 2001, 3, 7679

40. Silvana, S. M.; Suarez, P. A. Z.; de Souza, R. F.; Dupont, J. Polymer Bul. 1998, 40, 401-405.

41. Zimmermann, J.; Wassersceid, P.; Tkatchenko, I.; Stutzmann, S. Chem. Commun. 2002, 760-761.

42. Xu, L.; Chen, W.; Ross, J.; Xiao, J. Org. Lett. 2001, 3, 295-297.

43. Mo, J.; Xu, L.; Xiao, J. J. Am. Chem. Soc. 2005, 127, 751-760.

44. de Bellefon, C.; Pollet, E.; Grenouillet, P. J. Mol. Catal. A: Chemical 1999, 145, 121-126.

45. Kim, D. W.; Song, C. E.; Chi, D. Y. J. Am. Chem. Soc. 2002, 124, 10278-10279.

46. Kim, D. W.; Song, C. E.; Chi, D. Y. J. Org. Chem. 2003, 68, 42814285.

47. Kim, D. W.; Hong, D. J.; Seo, J. W.; Kim, H. S.; Kim, H. K. Song, C. E.; Chi, D. Y. J. Org. Chem. 2004, 69, 3186-3189.

48. Gerdes, J. M.; Keil, R. N.; Shulgin, A. T.; Mathis, C. A. J. Fluorine Chem. 1996, 78, 121-129.

49. Sun, W.; Xia, C.-G.; Wang, H.-W. Tetrahedron Lett. 2003, 44, 2409-2411.

50. Ohara, H.; Kiyokaneb, H.; Itoha, T. Tetrahedron Lett. 2002, 43, 3041-3044.

51. Song, C. E.; Roh, E. J. Chem. Commun. 2000, 837-838.

52. Song, C. E. unpublished results.

53. Jessop, P. G.; Stanley, R. R.; Brown, R. A.; Eckert, C. A.; Liotta, C. L.; Ngo, T. T.; Pollet, P. Green Chem. 2003, 5, 123-128.

54. Noyori, R. Asymmetric Catalysis in Organic Synthesis; John Wiley and Sons: New York, 1994.

55. Sun, Y.; Landau, R. N.; Wang, J.; LeBlond, C.; Blackmond, D. G J. Am. Chem. Soc. 1996, 118, 1348-1353.

56. Doherty, S.; Goodrich, P.; Hardacre, C.; Luo, H.-K.; Rooney, D. W.; Seddon, K. R.; Styring, P. Green Chem. 2004, 6, 63-67.

57. Meracz, I.; Oh, T. Tetrahedron Lett. 2003, 44, 6465-6468.

58. Toma, S.; Gotov, B.; Kmentova, I.; Solcaniova, E. Green Chem. 2000, 2, 149-151.

59. Kmentova, I.; Gotov, B.; Solcaniova, E.; Toma, S. Green Chem 2002, 4, 103-106.

60. List, B. Tetrahedron 2002, 58, 5573-5570.

61. List, B. Synlett. 2001, 1675-1686.

62. Sakthiviel, K.; Notz, W.; Bui, T.; Barbas III, C. F. J. Am. Chem. Soc. 2001, 123, 5260-5267.

63. Loh, T.-P.; Feng, L.-C.; Yang, H.-Y.; Yang, J.-Y. Tetrahedron Lett. 2002, 43, 8741-8743.

64. Kotrusz, P.; Kmentova, I.; Gotov, B.; Toma, S.; Solcaniova, E. Chem. Commun. 2002, 2510-2511.

65. Fraile, J. M.; Garcia, J. I.; Herrerias, C. I.; Mayoral, J. A.; Carrie, D.; Vaultier, M. Tetrahedron: Asymmetry 2001, 12, 1891-1894.

66. Oh, C. R.; Choo, D. J.; Shim, W. H.; Lee, D. H.; Roh, E. J.; Lee, S.-g.; Song, C. E. Chem. Commun. 2003, 1100-1101.

67. Guernik, A.; Wolfson, A.; Herskowitz, M.; Greenspoon, N.; Geresh, S. Chem. Commun. 2001, 2314-2315.

68. Sheldon, R. A.; Lau, R. M.; Sorgedrager, M. J.; van Rantwijk, F.; Seddon, K. R. Green Chem. 2002, 4, 147-151.

69. Howarth, J.; Hanlon, K.; Fayne, D.; McCormac, P. Tetrahedron Lett. 1997, 38, 3097-3100.

70. Pegot, B.; Vo-Thanh, G.; Gori, D.; Loupy, A. Tetrahedron Lett. 2004, 45, 6425-6428.

71. Ding, J.; Desikan, V.; Han, X.; Xiao, T. L.; Ding, R.; Jenks, W. S.; Armstrong, D. W. Org. Lett. 2005, 7, 335-337. 